\title{
Altered Regulation of Apolipoprotein A-IV Gene Expression in the Liver of the Genetically Obese Zucker Rat
}

\author{
Wolfgang Strobl, * Birgit Knerer, * Regina Gratzl, * Klaus Arbeiter, * Yen-chiu Lin-Lee, ${ }^{*}$ and Wolfgang Patsch* \\ ${ }^{*}$ Department of Pediatrics, University of Vienna, A-1090 Vienna, Austria; and ${ }^{\ddagger}$ Department of Medicine, \\ Baylor College of Medicine, Houston, Texas 77030
}

\begin{abstract}
apolipoprotein (apo) A-IV, a structural component of chylomicrons and high-density lipoproteins, may play a role in the catabolism of trigyceride-rich lipoproteins and in reverse cholesterol transport. To study the regulation of apoA-IV gene expression by genetic and nutritional factors, we determined the effect of a fish oil-rich and a sucrose-rich diet on apoA-IV gene transcription and nuclear and total cellular apoA-IV mRNA abundance in livers of genetically obese, hyperlipoproteinemic (fa/fa) Zucker rats and their lean ( $\mathrm{Fa} /-$ ) littermates. In obese rats fed chow, hepatic apoA-IV gene expression was more than twofold higher than in lean rats because of a posttranscriptional mechanism. apoA-I gene expression and apoCIII mRNA levels, studied as controls, were similar in both groups. The fish oil-rich diet reduced total cellular apoA-IV mRNA abundance transcriptionally to $34 \pm 4 \%$ of basal values in lean rats, but did not alter apoA-IV gene expression in obese rats. In contrast, this diet reduced apoA-I gene expression in both lean and obese animals. The sucrose-rich diet increased apoA-IV gene expression twofold in both lean and obese rats. Thus, genetic obesity alters the response of hepatic apoA-IV gene expression to a lipid-lowering diet rich in fish oil by a mechanism affecting transcriptional regulation. (J. Clin. Invest. 1993. 92:1766-1773.) Key words: apolipoproteins • gene expression • fish oil $\bullet$ Zucker rat • obesity
\end{abstract}

\section{Introduction}

Changes in plasma lipoprotein levels in response to dietary stimuli such as excess cholesterol and/or altered fatty acid composition differ among individuals $(1,2)$. Studies in animal models have shown that genetic components play a major role in the adaptive response of the lipid-transport system to dietary perturbations (3-5). Inherited differences in the regulation and/or structure of genes coding for apolipoproteins, lipoprotein receptors, and key enzymes of plasma lipoprotein metabo-

Address correspondence to Wolfgang Strobl, M.D., Department of Pediatrics, University of Vienna, Währinger Gürtel 18-20, A-1090 Vienna, Austria.

Received for publication 17 December 1992 and in revised form 5 April 1993.

\footnotetext{
${ }^{1}$ Abbreviations used in this paper: apoA-I, apoA-II, apoA-IV, apoB, apoC-II, apoC-III, and apoE, apolipoproteins A-I, A-II, A-IV, B, C-II, C-III, and E, respectively.

J. Clin. Invest.

(c) The American Society for Clinical Investigation, Inc.

$0021-9738 / 93 / 10 / 1766 / 08 \quad \$ 2.00$

Volume 92, October 1993, 1766-1773
}

lism may be critical for an individual's response to diet. Recent studies have, therefore, attempted to link polymorphisms in the human apolipoprotein B (apoB), ${ }^{1}$ apoE, and low-density lipoprotein receptor genes to dietary response patterns $(6,7)$.

Inbred strains of mice that exhibit large variations in basal and diet-induced expression of several apolipoprotein genes in the liver have provided useful models for studying the interaction of genetic and dietary factors in the regulation of apolipoprotein gene expression (8-11). The expression of the gene coding for apoA-IV appears to be particularly sensitive to dietary regulation in mouse liver. Hepatic apoA-IV mRNA abundance on a basal diet, as well as changes in apoA-IV gene expression in response to an atherogenic diet, varied by orders of magnitude among inbred strains of mice, whereas apoA-I and apoA-II gene expression varied much less $(8,10,11)$. apoA-IV is found mainly in chylomicrons, high-density lipoproteins, and the lipoprotein-free plasma fraction $(12,13)$ and is synthesized in the liver and intestine in mice and rats (14). Although the function of apoA-IV remains to be determined in detail, both in vitro and in vivo studies suggest a role of apoAIV in triglyceride transport (15-17).

In genetically obese Zucker rats, used as a model for human obesity (18), the production of apoA-IV by the liver and the abundance of hepatic apoA-IV mRNA are severalfold higher than in lean littermates $(19,20)$. The obese Zucker rat is characterized by autosomal recessive obesity linked to an allele termed fa, which has recently been mapped to chromosome 5 (21). Homology of this allele to the mouse diabetes $(\mathrm{db})$ gene has been suggested (21). Obese (fa/fa) Zucker rats develop marked hyperlipoproteinemia, a result of overproduction of very low density lipoproteins enriched in triglyceride (22-24). Lean $(\mathrm{Fa} /-)$ Zucker rats are normolipemic.

As in mice, hepatic apoA-IV gene expression in rats is subject to dietary regulation. A sucrose-rich diet increases triglyceride production by the liver and upregulates hepatic apoA-IV gene transcription (25), whereas diets rich in fish oil reduce hepatic triglyceride production and decrease the net production of apoA-IV in primary rat hepatocyte cultures (26). We, therefore, reasoned that the obese Zucker rat, like the inbred mice, may serve as a model to study the interaction of genetic and dietary factors in the regulation of apoA-IV gene expression.

To gain insight into the mechanism that increases basal apoA-IV gene expression in liver of obese Zucker rats, we measured apoA-IV gene transcription rates and nuclear and total cellular apoA-IV mRNA abundance in obese and lean Zucker rats fed rat chow. To determine whether genetic obesity alters dietary influences on apolipoprotein gene expression, we evaluated hepatic apoA-IV and apoA-I gene expression in obese and lean Zucker rats fed a fish oil-rich or sucrose-rich diet.

We report that basal hepatic apoA-IV mRNA abundance in obese Zucker rats is increased over that in lean rats by a posttranscriptional mechanism. The fish oil diet markedly de- 
creased hepatic apoA-IV gene transcription in lean Zucker rats, but had no effect on the enhanced hepatic apoA-IV gene expression in genetically obese rats. For apoA-I, basal gene expression was similar between obese and lean Zucker rats, as was the effect of fish oil feeding on gene expression. The effect of sucrose feeding did not vary by type of rat for either apoA-IV or apoA-I gene expression.

\section{Methods}

The $5^{\prime}-\alpha-\left[{ }^{2} \mathrm{P}\right]$ UTP $(3,000 \mathrm{Ci} / \mathrm{mM})$ and $5^{\prime}-\alpha-\left[{ }^{2} \mathrm{P}\right] \mathrm{dCTP}(2,000 \mathrm{Ci} /$ $\mathrm{mM}$ ) were obtained from New England Nuclear (Wilmington, DE), restriction enzymes and RNase-free DNase I from Boehringer Mannheim (Mannheim, Germany), and Zeta Probe ${ }^{\star}$ nylon membranes from Bio-Rad Laboratories (Richmond, CA). Nitrocellulose (BA 85) was purchased from Schleicher and Schuell (Dassel, Germany).

Male obese ( $\mathrm{fa} / \mathrm{fa}$ ) and lean $(\mathrm{Fa} /-)$ Zucker rats, 8 wk of age, were obtained from Harlan Olac Inc. (Bicester, England) (animal set I) or IFFA Credo (L'Arbresle, France) (animal set II). The rats were housed in a room with a 12-h light cycle (7-19 h). Rats were fed regular rat chow, a fish oil-rich diet, or a sucrose-rich diet for 3 wk ad lib. Rat chow (Laboratory Rodent Diet; Purina Mill Inc., Richmond, IN) contained $26 \%$ (wt/wt) protein, $54 \%$ carbohydrate, $6 \%$ fiber, $6 \%$ fat, $7 \%$ minerals and trace elements, and vitamins. The fish-oil diet (High Menhaden Oil Diet, ICN, Cleveland, OH) contained 20\% (wt/wt) menhaden oil, $1 \%$ corn oil, $20 \%$ casein, $33 \%$ sucrose, $5 \%$ alphacel, $15 \%$ cornstarch, $4 \%$ mineral mixture, $0.3 \%$ DL-methionine, $0.12 \% \alpha$-tocopherol $(250 \mathrm{IU} / \mathrm{g})$, and $1.2 \%$ vitamin mixture. The sucrose-rich diet (High Carbohydrate Diet, ICN) contained 68\% (wt/wt) sucrose, $18 \%$ casein, $8 \%$ cottonseed oil, $2 \%$ brewer's yeast, $4 \%$ salt mix USPII, vitamins, and trace elements. Obese Zucker rats on chow, the fish-oil diet, or the sucrose-rich diet gained significantly more weight than lean Zucker rats on the same diet $(3.4 \pm 0.5$ to $4.1 \pm 0.7 \mathrm{~g} / \mathrm{d}$ for obese vs. $1.7 \pm 0.6$ to $2.5 \pm 0.4 \mathrm{~g} / \mathrm{d}$ for lean, mean $\pm \mathrm{SD}, P<0.05$, analysis of variance). The average weight gains in obese and lean Zucker rats were not influenced by the three different diets. The average weight was $478 \pm 18$ $\mathrm{g}$ for obese and $353 \pm 10 \mathrm{~g}$ for lean rats (mean $\pm \mathrm{SD}, 28$ lean and 28 obese rats).

On rat chow, mean plasma trigycerides and total cholesterol were $277 \pm 106$ and $138 \pm 18 \mathrm{mg} / \mathrm{dl}$ in obese and $43 \pm 20$ and $73 \pm 10 \mathrm{mg} / \mathrm{dl}$ in lean rats, respectively (mean $\pm \mathrm{SD}, n=11, P<0.001$ for both triglyceride and cholesterol, analysis of variance), as determined by enzymatic methods $(27,28)$. The triglyceride-lowering effect of fish oil diet in obese Zucker rats described previously (29) was confirmed in our studies. Plasma triglyceride decreased from $277 \pm 106$ to $171 \pm 56 \mathrm{mg} / \mathrm{dl}$ ( 11 rats per group, $P<0.01)$. The fish oil diet increased total plasma cholesterol from $138 \pm 18$ to $178 \pm 30 \mathrm{mg} / \mathrm{dl}(P<0.01)$ in obese rats. The sucrose-rich diet increased plasma triglycerides from $25 \pm 4$ to $155 \pm 101$ $\mathrm{mg} / \mathrm{dl}$ in lean rats $(P<0.01$, analysis of variance, 6 rats per group $)$. In obese rats fed the sucrose diet, plasma triglyceride levels did not differ significantly from those in obese controls fed chow $(291 \pm 76$ vs. $253 \pm 92 \mathrm{mg} / \mathrm{dl}$ in controls, 6 rats per group). The sucrose-rich diet did not affect plasma cholesterol levels $(98 \pm 11$ vs. $81 \pm 5 \mathrm{mg} / \mathrm{dl}$ in lean rats, and $161 \pm 14$ vs. $150 \pm 8 \mathrm{mg} / \mathrm{dl}$ in obese rats fed chow or sucrose diet, respectively; 6 rats per group).

On the day on which rats were killed, food was removed at 8 a.m., and $1-6 \mathrm{~h}$ later the rats were anesthetized by $5 \mathrm{mg}$ per $100 \mathrm{~g}$ i.p. sodium pentobarbital before collection of blood from the inferior vena cava and removal of livers.

The recombinant plasmids used in this study were pGEM- $3 Z$ plasmids containing full-length cDNA inserts coding for apoA-IV (25), apoA-I (kindly provided by Dr. L. Chan, Baylor College of Medicine, Houston, TX), apoC-III (25), and mouse $\beta_{2}$ microglobulin (30). The probes were cut from the vectors with EcoRI, isolated by agarose gel electrophoresis, and labeled with $\left[{ }^{32} \mathrm{P}\right] \mathrm{dCTP}$ by random priming ( 31 ).

Total RNA was extracted from liver tissue by the guanidine hydrochloride method (32). Relative abundance of apoA-I, apoA-IV, or apoC-III mRNA was determined by quantitative slot blotting (32).
Total liver RNA was denatured with $1 \mathrm{M}$ glyoxal, 50\% dimethyl sulfoxide and separated by electrophoresis in $1.2 \%$ agarose. Northern transfer of RNA to Zeta Probe ${ }^{\circledR}$ nylon membranes and hybridization were performed as outlined by Thomas (33) using the conditions described recently (34). Relative abundance of mRNA was determined from band intensity quantified by soft laser densitometry. Probe stripping and rehybridization were carried out according to the manufacturer's recommendations. Hybridization to a mouse $\beta_{2}$-microglobulin cDNA probe was used to ensure loading of equal amounts of RNA per slot (data not shown).

Isolated liver cell nuclei were prepared by sucrose density gradient centrifugation according to Northemann et al. (35) as previously described (34). Cell-free transcription was performed by the method of Birch and Schreiber (36) as previously described $(34,37)$. Under our experimental conditions, transcription was DNA dependent, and RNA polymerase II activity amounted to $55 \%$ of total transcription, as previously reported (34). Transcription from the apolipoprotein genes was abolished by $2.5 \mu \mathrm{g} / \mathrm{ml} \alpha$-amanitin. The newly synthesized ${ }^{32} \mathrm{P}$-labeled transcripts of the apoA-I and apoA-IV genes were quantitated by hybridization to an excess ( $5 \mu \mathrm{g}$ ) of plasmid containing apoA-I or apoAIV cDNA inserts immobilized on nitrocellulose membranes by dot blotting as in earlier experiments $(25,37)$. Nonrecombinant plasmid pGEM-3Z was used to determine nonspecific hybridization. Radioactivity was eluted from the filters with $0.3 \mathrm{M} \mathrm{NaOH}$, and the samples were counted for $20 \mathrm{~min}$ in a liquid scintillation counter. The relative rates of apoA-I and apoA-IV gene transcription were calculated by subtracting the $\mathrm{cpm}^{32} \mathrm{P}$ bound to the filters containing nonrecombinant plasmids (1-2 ppm) from the $\mathrm{cpm}^{32} \mathrm{P}$ bound to the filters with plasmids containing the apoA-I or apoA-IV cDNA inserts, and then dividing the cpm ${ }^{32} \mathrm{P}$ bound by the $\left[{ }^{32} \mathrm{P}\right]$ RNA input. $\left[{ }^{3} \mathrm{H}\right] \mathrm{cRNA}$ standards for apoA-I and apoA-IV were transcribed from the plasmid templates using Sp6 or T7 polymerase as described by Melton et al. (38). To determine hybridization efficiency, $1,000 \mathrm{cpm}$ of the appropriate $\left[{ }^{3} \mathrm{H}\right] \mathrm{cRNA}$ standard was included in the hybridization reaction. Transcription rates were corrected for hybridization efficiency (indicated in legends to Tables I and II ) and are given as parts per million of $\left[{ }^{32} \mathrm{P}\right]-$ RNA input. No significant differences in the hybridization efficiency were found between the experimental groups.

Nuclear RNA was extracted using guanidine isothiocyanate and isolated by $\mathrm{CsCl}$ density gradient ultracentrifugation following the protocol of Lamers et al. (39) as reported previously (37). Nuclear RNA was analyzed by Northern blotting and quantitative slot blotting followed by soft laser densitometry of autoradiograms.

For comparison of mean values, one-way analysis of variance and Scheffe tests were performed using the SPSS/PC+ program package. Results are given as mean values $\pm \mathrm{SD}$.

\section{Results}

Basal apoA-IV and apoA-I gene expression in livers of obese $(\mathrm{fa} / \mathrm{fa})$ and lean $(\mathrm{Fa} /-)$ Zucker rats. Among the rats fed chow, total hepatocellular apoA-IV mRNA abundance was at least twofold higher in obese than in lean rats, as determined by quantitative slot blotting (Table I and Fig. 1). The increased apoA-IV mRNA abundance in obese Zucker rats is consistent with earlier reports (20). Northern blotting of total cellular RNA showed a single apoA-IV mRNA species of expected size and confirmed the data obtained by slot blotting (Fig. 2).

To determine at what level of gene expression apoA-IV expression is increased in obese Zucker rats, we measured apoA-IV gene transcription by run-on assays using isolated liver cell nuclei. apoA-IV gene transcription did not differ between obese and lean Zucker rats in three run-on assays performed with nuclei from two independent sets of animals ( Table I and Fig. 1). Thus, posttranscriptional mechanisms must be responsible for the higher apoA-IV mRNA abundance in obese Zucker rats. 
Table I. Effects of a Fish-Oil Diet vs. Chow on Hepatic apoA-IV Gene Expression in Lean and Obese Zucker Rats

\begin{tabular}{|c|c|c|c|c|c|c|c|}
\hline \multirow[b]{2}{*}{ Group } & \multirow[b]{2}{*}{ Diet } & \multirow[b]{2}{*}{$\begin{array}{l}\text { Animal } \\
\text { set }\end{array}$} & \multirow[b]{2}{*}{ Exp. } & \multicolumn{2}{|c|}{ apoA-IV gene transcription } & \multirow{2}{*}{$\begin{array}{c}\text { Nuclear apoA-IV } \\
\text { RNA abundance } \\
\text { (percent of lean control) }\end{array}$} & \multirow{2}{*}{$\begin{array}{l}\text { Total cellular apoA-IV } \\
\text { mRNA abundance } \\
\text { (percent of lean control) }\end{array}$} \\
\hline & & & & ppm & $\begin{array}{c}\text { Transcription } \\
\text { (percent of lean control) }\end{array}$ & & \\
\hline \multirow{5}{*}{$\begin{array}{l}\text { Lean } \\
(\mathrm{Fa} /-)\end{array}$} & Chow & I & 1 & 157 & & & \\
\hline & & & & 171 & & & \\
\hline & & & & & $100 \pm 17^{*}$ & & $100 \pm 21$ \\
\hline & & I & 2 & $103 \pm 23$ & & & \\
\hline & & II & 3 & $182 \pm 22$ & $100 \pm 12$ & $100 \pm 15$ & $100 \pm 9$ \\
\hline \multirow{4}{*}{$\begin{array}{l}\text { Obese } \\
(\mathrm{fa} / \mathrm{fa})\end{array}$} & Chow & I & 1 & $176 \pm 9$ & & & \\
\hline & & & & & $111 \pm 17$ & & $214 \pm 20^{\ddagger}$ \\
\hline & & I & 2 & $120 \pm 26$ & & & \\
\hline & & II & 3 & $203 \pm 26$ & $112 \pm 14$ & $342 \pm 71^{5}$ & $379 \pm 53^{\ddagger}$ \\
\hline \multirow{5}{*}{$\begin{array}{l}\text { Lean } \\
(\mathrm{Fa} /-)\end{array}$} & Fish oil & I & 1 & 44 & & & \\
\hline & & & & 49 & & & \\
\hline & & & & & $20 \pm 10^{\ddagger}$ & & $34 \pm 4^{\ddagger}$ \\
\hline & & I & 2 & $15 \pm 9$ & & & \\
\hline & & II & 3 & $48 \pm 6$ & $27 \pm 3^{\ddagger}$ & $25 \pm 14^{\S}$ & $33 \pm 11^{\ddagger}$ \\
\hline \multirow{4}{*}{$\begin{array}{l}\text { Obese } \\
(\mathrm{fa} / \mathrm{fa})\end{array}$} & Fish oil & I & 1 & $145 \pm 5$ & & & \\
\hline & & & & & $88 \pm 7$ & & $183 \pm 13^{\ddagger}$ \\
\hline & & I & 2 & $90 \pm 10$ & & & \\
\hline & & II & 3 & $196 \pm 12$ & $108 \pm 7$ & $383 \pm 28^{8}$ & $405 \pm 72^{\ddagger}$ \\
\hline
\end{tabular}

apoA-IV gene transcription rates were determined in three run-on assays using isolated liver cell nuclei from two sets of animals (I and II) fed fish oil diet or rat chow for $3 \mathrm{wk}$. Pooled nuclei from 5 rats per group were used in experiments 1 and 2 , and three pools of two rats each group were used in experiment 3 . Hybridizations of newly synthesized ${ }^{32} \mathrm{P}$ nuclear RNA were performed in duplicate to quintuplicate. ${ }^{32} \mathrm{P}$ nuclear RNA input was $6,4.5$, and $8 \times 10^{6} \mathrm{cpm}$ in experiments 1,2 and 3, respectively. Results are corrected for hybridization efficiency $(39 \pm 5$, $16 \pm 2$, and $34 \pm 3 \%$ in experiments 1,2 , and 3 , respectively) determined by ${ }^{3} \mathrm{H}$-apoA-IV cRNA standards $(1,000 \mathrm{cpm})$ included in the reactions and expressed as ppm of ${ }^{32} \mathrm{P}$ nuclear RNA input. The abundance of nuclear apoA-IV RNA and total cellular apoA-IV mRNA was determined in duplicate to quadruplicate by quantitative slot blotting of RNA pooled from five animals per group for animal set I and in three pools of two rats in animal set II. Results are given as means \pm SD. ${ }^{*}$ Combined results from experiments 1 and 2 . ${ }^{\ddagger}$ Significantly different from lean (Fa/-) controls fed chow, $P<0.01$, analysis of variance, Scheffé test. ${ }^{8}$ Significantly different from lean $(\mathrm{Fa} /-)$ controls fed chow, $P<0.05$ analysis of variance, Scheffé test.

To distinguish between posttranscriptional events controlling mRNA maturation and stabilization of mature mRNA in the cytoplasm, we measured the abundance of nuclear apoAIV RNA in obese and lean Zucker rats. Nuclear apoA-IV RNA abundance was 3.4 times higher in obese than in lean rats, as determined by quantitative slot blotting, and accounted for the increase in total cellular apoA-IV mRNA abundance (Table I, animal set II, and Fig. 1). Northern blotting of nuclear RNA

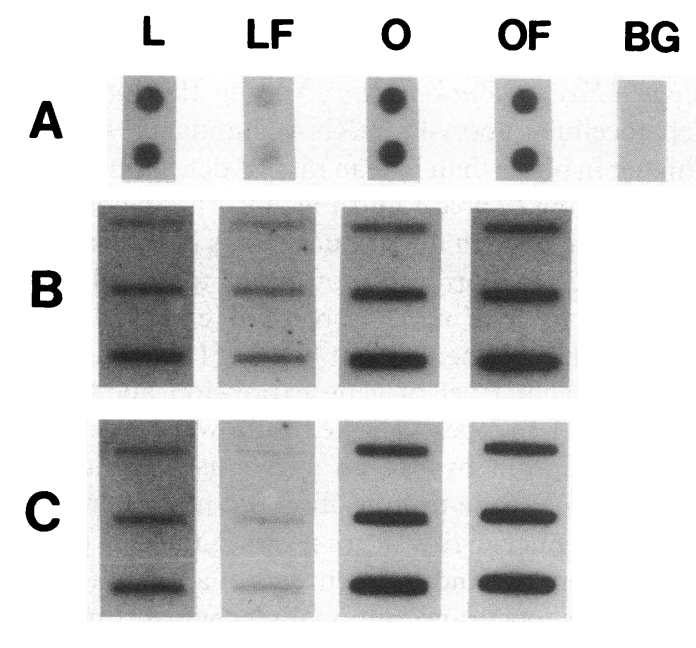

ApoA-IV

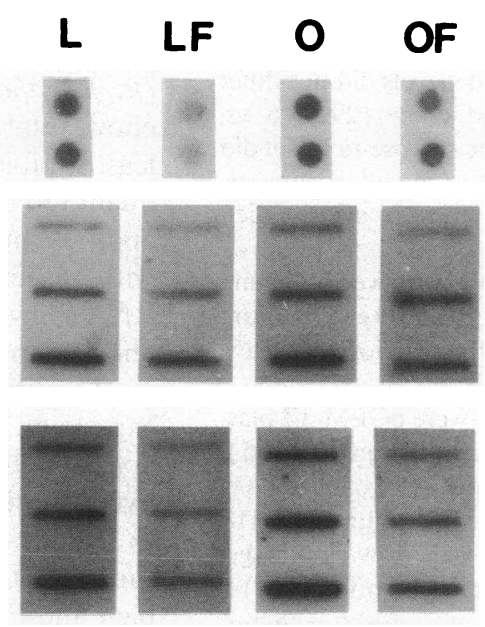

ApoA-I
Figure 1. Effect of a fish oil diet fed for 3 wk on hepatic apoA-I and apoA-IV gene transcription and nuclear and total cellular mRNA abundance in lean and genetically obese Zucker rats. $(A)$ Representative dot blots from run-on transcription assays using pooled liver cell nuclei from 5 animals per group. $B G$, background hybridization to nonrecombinant plasmid pGEM3Z. (B) Representative slot blots of nuclear RNA pooled from five animals per group hybridized to ${ }^{32} \mathrm{P}$-labeled full-length apoA-IV and apoA-I cDNA probes. $(C)$ Representative slot blots of total liver RNA pooled from five animals per group hybridized to ${ }^{32} \mathrm{P}$-labeled fulllength apoA-IV and apoA-I cDNA probes. $L$, lean/chow; $L F$, lean/fish 


\section{ApoA-IV}

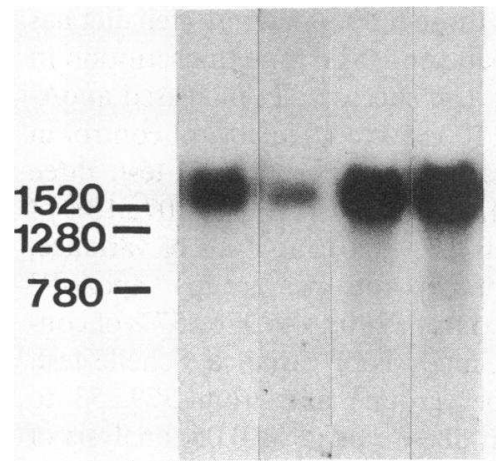

L LF O OF
ApoA-I

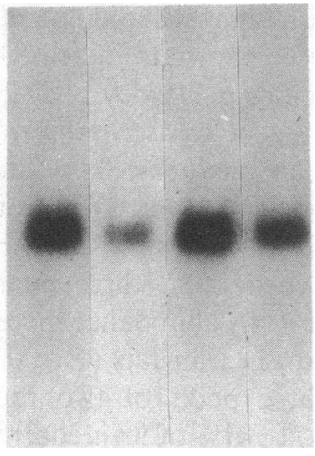

L LF O OF

Figure 2. Effect of fish oil diet on hepatic apoA-I and apoA-IV mRNA abundance in lean and obese Zucker rats. Total cellular RNA was isolated from livers of lean and obese Zucker rats fed a fish oil-rich diet or rat chow for $3 \mathrm{wk}$. Samples ( $20 \mu \mathrm{g}$ of pooled RNA from six rats per group) were analyzed by Northern blotting using full-length apoA-IV and apoA-I cDNA probes for hybridization. $L$, lean/chow; $L F$, lean/fish oil; $O$, obese/chow; $O F$, obese/fish oil. Molecularweight standards are shown to the left.

confirmed the higher abundance of apoA-IV RNA established by slot blotting and showed, in addition to mature apoA-IV mRNA, three larger apoA-IV RNA species (Fig. 3). The proportions of nuclear apoA-IV RNA species did not differ between obese and lean rats, as judged by densitometry of Northern blots. Given the similarity in apoA-IV transcription rates, these data are consistent with increased stability and/or enhanced processing of the primary apoA-IV gene transcript in obese rats.

apoA-I gene expression was studied to validate the enhanced apoA-IV gene expression in obese Zucker rats, since previous studies showed the net production of apoA-I in hepatic perfusates to be similar in obese and lean Zucker rats (24). To identify genetic influences on the hepatic expression of the apoA-I and apoA-IV genes was also of interest, since these genes are closely linked to each other and to the apoC-III gene (17). Consistent with the results in hepatic perfusates (24), abundance of hepatic apoA-I mRNA did not differ between obese and lean Zucker rats (Table II and Figs. 1 and 2). Similarly, there was no difference in apoA-I gene transcription rates or nuclear apoA-I RNA abundance (Table II and Figs. 1 and 3 ).

As an additional control, we determined the mRNA abundance of apoC-III by quantitative slot blotting and Northern blotting. Although apoC-III protein production has been reported to be increased in obese Zucker rats (24), hepatic apoCIII mRNA abundance was comparable between obese and lean animals $(93 \pm 15 \%$ in obese and $100 \pm 13 \%$ in lean, three pools of two animals each). Northern analysis confirmed these results (data not shown). These results suggest that apoC-III production in obese Zucker rats may be increased at the translational or posttranslational level, as has been proposed for the increased hepatic apoC-III production in Sprague-Dawley rats in response to a sucrose-rich diet (25).

Effect of fish oil diet on hepatic apoA-IV and apoA-I gene expression. To study the effect of a fish oil diet on hepatic apoA-IV gene expression, we measured total cellular and nuclear apoA-IV mRNA abundance and apoA-IV gene transcription in livers of lean and obese Zucker rats fed a diet containing $20 \%$ (wt/wt) menhaden oil or rat chow for $3 \mathrm{wk}$. The fish oil diet decreased total cellular hepatic apoA-IV mRNA abundance of lean Zucker rats to $34 \pm 4 \%$ of its abundance in lean rats fed chow $(P<0.01$, analysis of variance, Scheffé test; Table I and Figs. 1 and 2). In contrast, the fish oil diet did not de-
ApoA-IV

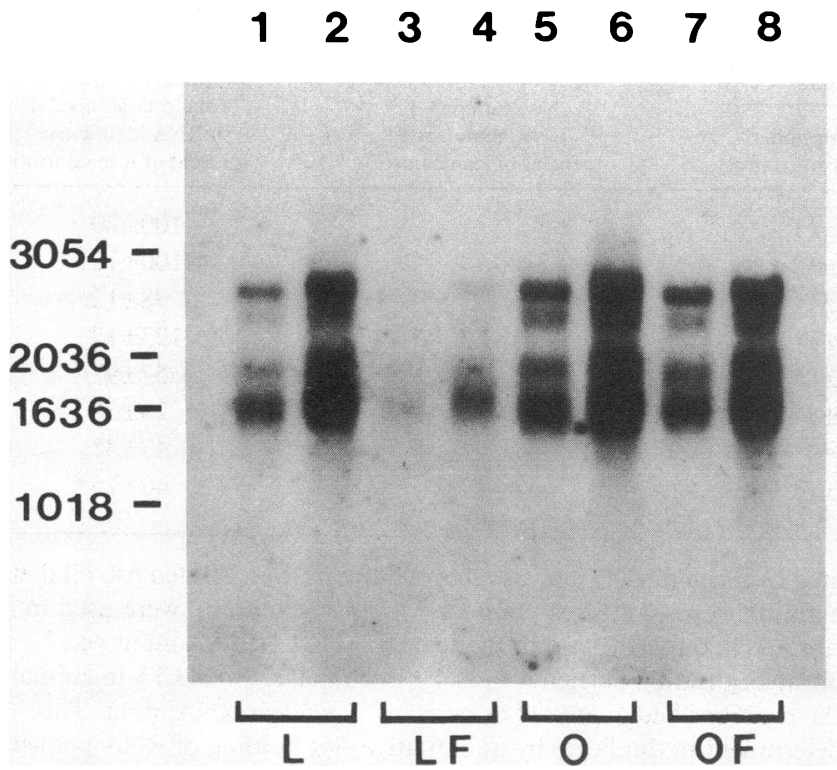

\section{ApoA-I}
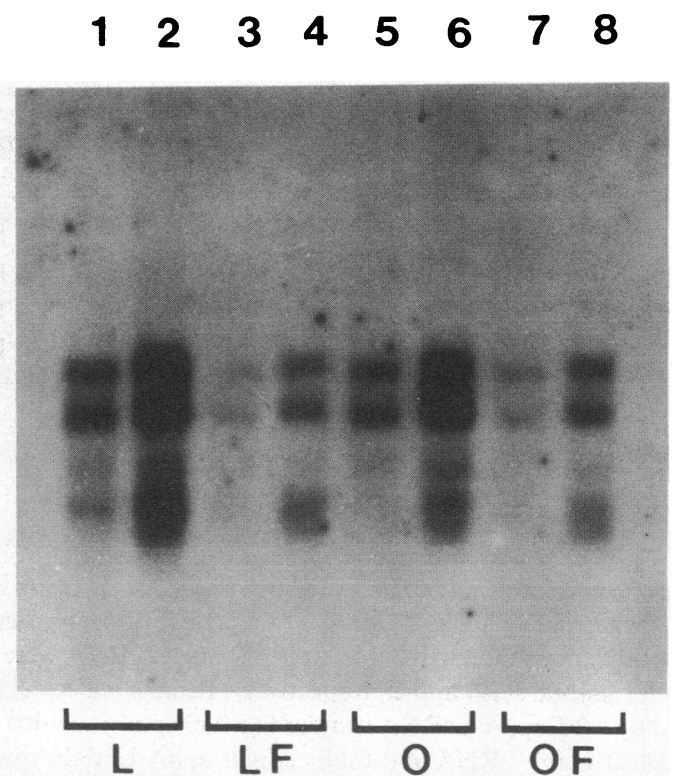

Figure 3. Effect of fish-oil diet vs. rat chow on nuclear apoA-I and apoA-IV RNA abundance in lean and genetically obese Zucker rats. Nuclear RNA was isolated from five animals per group, and $15 \mu \mathrm{g}$ (lanes $1,3,5$, and 7) or $30 \mu \mathrm{g}$ (lanes $2,4,6$, and 8 ) was analyzed by Northern blotting. $L$, lean/chow; $L F$, lean/fish oil; $O$, obese/chow; $O F$, obese/fish oil. Molecular-weight standards are shown to the left. 
crease apoA-IV mRNA abundance in obese rats. Northern blots showed no change in the size of total cellular apoA-IV mRNA and confirmed the data obtained by slot blotting (Fig. 2).

The fish oil diet decreased apoA-IV transcription rates to less than one third of control levels in liver cell nuclei from lean rats. This decrease accounted quantitatively for the decrease in total cellular apoA-IV mRNA abundance (Table I and Fig. 1). In contrast, apoA-IV gene transcription did not decrease in obese rats in response to the fish oil diet. Furthermore, the abundance of nuclear apoA-IV mRNA precursors decreased in lean but not in obese fatty rats (Table I and Figs. 1 and 3 ). Thus, the fish oil diet markedly decreased apoA-IV gene expression in lean Zucker rats at the transcriptional level, but had no effect on apoA-IV gene transcription or abundance of nuclear and total cellular apoA-IV mRNA in obese Zucker rats.

To determine whether the different effect of the fish oil diet on apoA-IV gene transcription in lean and obese rats was specific to this gene, we studied dietary effects on apoA-I gene expression and apoC-III mRNA abundance. Unlike apoA-IV mRNA abundance, apoA-I mRNA abundance decreased twoto threefold in both lean and obese rats fed the fish oil diet (Table II and Figs. 1 and 2). In lean rats, the decrease in apoA-I mRNA abundance could be explained quantitatively by the decrease in apoA-I gene transcription and nuclear RNA abundance. In obese rats, the abundance of total cellular apoA-I mRNA decreased to a greater extent than apoA-I gene transcription and nuclear apoA-I RNA abundance. Neither in lean nor in obese rats did the fish oil diet reduce the abundance of apoC-III mRNA ( $100 \pm 13$ vs. $89 \pm 9 \%$ of control in lean rats fed chow or fish oil, and $93 \pm 15$ vs. $100 \pm 19 \%$ of control in obese rats fed chow or fish oil, three pools of two rats each, quantitative slot blotting).

Effect of sucrose-rich diet on hepatic apoA-IV and apoA-I gene expression. The sucrose-rich diet was used to examine whether basal hepatic apoA-IV gene transcription rates in obese Zucker rats could be altered by dietary factors other than fish oil, which did not affect those rates. A sucrose-rich diet has been shown to increase hepatic apoA-IV gene transcription in Sprague-Dawley rats (25). The sucrose diet increased apoAIV gene transcription from $100 \pm 16$ to $197 \pm 30 \%$ of control in lean rats $(P<0.05$, analysis of variance, Scheffe test, three pools of two rats per group), and from $113 \pm 14$ to $207 \pm 18 \%$ of control in obese Zucker rats $(P<0.01$, analysis of variance, Scheffé test, three pools of two rats per group). apoA-IV mRNA abundance increased from $100 \pm 9$ to $376 \pm 57 \%$ of control in lean rats $(P<0.05$, analysis of variance, Scheffé test, three pools of two rats per group) and from $379 \pm 53$ to $671 \pm 81 \%$ of lean control in obese rats $(P<0.05$, analysis of variance, Scheffé test, three pools of two rats per group). Thus, the stimulation of apoA-IV gene transcription in response to a sucrose-rich diet was maintained in both lean and obese Zucker rats. The sucrose-rich diet did not alter the transcription rate of the apoA-I gene $(92 \pm 13 \%$ of control in lean and $115 \pm 10 \%$ of control in obese Zucker rats, three pools of two rats per group), as reported earlier in Sprague-Dawley rats (25).

\section{Discussion}

Our experiments demonstrate that genetic obesity in the Zucker rat is associated with specific changes in the hepatic expression of the apoA-IV gene. Basal apoA-IV gene expression is increased by a posttranscriptional mechanism operating within the nucleus. Furthermore, genetic obesity in Zucker rats renders the apoA-IV but not the apoA-I gene unresponsive to transcriptional downregulation by a fish oil diet.

Posttranscriptional stabilization or more efficient processing (or both) of apoA-IV mRNA precursors in liver cell nuclei of obese Zucker rats is suggested by increased abundance of nuclear and cytoplasmic apoA-IV RNA and similar apoA-IV transcription rates in liver cell nuclei of lean and obese Zucker rats (Table I and Figs. 1 and 3). Regulation of apolipoprotein

Table II. Effects of Fish-Oil Diet on Hepatic apoA-I Gene Expression in Lean and Obese Zucker Rats

\begin{tabular}{|c|c|c|c|c|c|c|}
\hline \multirow[b]{2}{*}{ Group } & \multirow[b]{2}{*}{ Diet } & \multirow[b]{2}{*}{$\begin{array}{c}\text { Animal } \\
\text { set }\end{array}$} & \multicolumn{2}{|c|}{ apoA-I gene transcription } & \multirow{2}{*}{$\begin{array}{c}\text { Nuclear apoA-I } \\
\text { RNA abundance } \\
\text { (percent of lean control) }\end{array}$} & \multirow{2}{*}{$\begin{array}{l}\text { Total cellular apoA-I } \\
\text { mRNA abundance } \\
\text { (percent of lean control) }\end{array}$} \\
\hline & & & ppm & $\begin{array}{c}\text { Transcription } \\
\text { (percent of lean control) }\end{array}$ & & \\
\hline Lean & Chow & I & $74 \pm 8$ & $100 \pm 11$ & & $100 \pm 20$ \\
\hline$(\mathrm{Fa} /-)$ & & II & $54 \pm 6$ & $100 \pm 12$ & $100 \pm 9$ & $100 \pm 12$ \\
\hline Obese & Chow & I & $94 \pm 8$ & $127 \pm 11$ & & $98 \pm 12$ \\
\hline$(\mathrm{fa} / \mathrm{fa})$ & & II & $57 \pm 6$ & $105 \pm 11$ & $118 \pm 30$ & $123 \pm 12$ \\
\hline Lean & Fish oil & I & $27 \pm 6^{*}$ & $37 \pm 8^{*}$ & & $57 \pm 9 *$ \\
\hline$(\mathrm{Fa} /-)$ & & II & $28 \pm 4^{*}$ & $51 \pm 8^{*}$ & $41 \pm 17^{*}$ & $28 \pm 3^{*}$ \\
\hline Obese & Fish oil & I & $61 \pm 7^{\ddagger}$ & $82 \pm 9^{\ddagger}$ & & $47 \pm 4^{*}$ \\
\hline$(f a / f a)$ & & II & $44 \pm 4^{\ddagger}$ & $81 \pm 7^{\ddagger}$ & $66 \pm 21^{\S}$ & $40 \pm 15^{*}$ \\
\hline
\end{tabular}

apoA-I gene transcription rates were determined by run-on assays using isolated liver cell nuclei from two sets of animals (I and II) fed fish oil diet or rat chow for $3 \mathrm{wk}$. Pooled nuclei from five rats per group were used in animal set $I$ and three pools of two rats each group were used in animal set II. Hybridizations of newly synthesized ${ }^{32} \mathrm{P}$ nuclear RNA were performed in duplicate to quintuplicate. ${ }^{32} \mathrm{P}$ nuclear RNA input was 7 and $9 \times 10^{6} \mathrm{cpm}$ for animal sets I and II, respectively. Results are corrected for hybridization efficiency (32 $\pm 4 \%$ in animal set I, $18 \pm 3 \%$ in animal set II) determined by a ${ }^{3} \mathrm{H}$-apoA-I cRNA standard $(1,000 \mathrm{cpm})$ included in the reactions and expressed as ppm of ${ }^{32} \mathrm{P}$ nuclear RNA input. The abundance of nuclear apoA-I RNA and total cellular apoA-I mRNA was determined in duplicate by quantitative slot blotting of RNA pooled from five animals per group for animal set $I$ and in three pools of two rats in animal set II. Results are given as means \pm SD. $*$ Significantly different from lean $(\mathrm{Fa} /-)$ controls fed chow, $P<0.01$, analysis of variance, Scheffe test. ${ }^{\ddagger}$ Significantly different from obese (fa/fa) controls fed chow, $P<0.05$, analysis of variance, Scheffé test. ${ }^{\S}$ Significantly different from obese (fa/fa) controls fed chow, $P<0.01$, analysis of variance, Scheffé test. 
gene expression at the level of mRNA maturation has been previously described. Nuclear processing of apoA-I RNA species is increased in chronic hyperthyroidism; this increase results in greater abundance of cytoplasmic apoA-I mRNA (37). The enhanced apoA-I mRNA maturation in livers of chronic hyperthyroid rats is associated with specific changes in steadystate levels of individual nuclear apoA-I RNA species, implying protection of an mRNA precursor from degradation or more efficient splicing (40). However, the mechanism altering nuclear apoA-IV RNA maturation in obese Zucker rats appears to be different, since the proportions of nuclear apoA-IV mRNA precursors were similar in obese and lean Zucker rats (Fig. 3). We, therefore, hypothesize that genetic obesity may affect an early step in the apoA-IV mRNA maturation pathway preceding splicing, i.e., it may enhance the stability of the primary transcript. Such a mechanism has been suggested for the regulation of the human liver/bone/kidney-type alkaline phosphatase gene in osteoblast and nonosteoblast cell lines (41).

Changes in RNA metabolism in the nucleus or cytoplasm also account for the large difference in basal hepatic apoA-IV mRNA abundance between the inbred mouse strains C57BL/ 6 and $129 / \mathrm{J}$ (10). In 129/J mice, the altered mRNA stability may result from a 12-bp deletion within a polymorphic tandem repeat region at the $3^{\prime}$ end of the apoA-IV gene, but trans-acting factors may play a role as well (42). Even though the studies in inbred strains of mice did not distinguish between nuclear and cytoplasmic RNA stabilization, it is conceivable that homologous sequences may play a role in the altered maturation of apoA-IV mRNA that is observed in obese Zucker rats. Another example of posttranscriptional regulation of apoA-IV gene expression is the increased abundance of mature apoA-IV mRNA in chronic hyperthyroidism. In this setting, the stability of apoA-IV mRNA is enhanced in the cytoplasm (40). Changes in hepatic apoA-IV mRNA abundance have also been demonstrated in a number of other metabolic conditions, but the underlying mechanisms have not been elucidated $(43,44)$.

Fish oil diets reduce the net production of apolipoproteins in rat liver at different levels of gene expression. Posttranslational events have been implicated in the downregulation of apoB secretion, whereas decreased mRNA abundance accounted for reduced apoE production (26). Net production of apoA-IV in hepatocyte cultures from rats fed a fish oil diet is reduced (26). Our studies in lean Zucker rats are consistent with these results and show that a fish oil diet reduces the abundance of hepatic apoA-IV mRNA and that the reduction can be accounted for by downregulation of transcription. The physiological significance of the decreased hepatic apoA-IV expression is not fully understood. Although the detailed functions of apoA-IV remain to be established, there is evidence to suggest that apoA-IV plays a role in triglyceride transport. Plasma apoA-IV levels are correlated with plasma trigyceride levels (16), and the level of apoA-IV gene expression resembles that of triglyceride transport during development $(17,43)$. ApoAIV enhances the transfer of apoC-II to trigyceride-rich lipoproteins in vitro and may, therefore, facilitate the catabolism of triglyceride-rich lipoproteins in the circulation (15). Fish oil diets greatly reduce the synthesis and secretion of very low density lipoprotein triglycerides in humans, experimental animals, and cultured hepatocytes $(26,45-47)$. These diets exert their effect, at least in part, by reducing the activity of lipogenic enzymes in liver (48). Reduced activity levels of at least two enzymes, fatty acid synthase and $S_{14}$, result from transcrip- tional down-regulation (49). It is thus conceivable that the fish oil diet alters the balance of trans factors and thereby integrates the expression of a gene network that includes the apoA-IV gene and controls triglyceride metabolism. A number of cis and trans factors regulating basal and tissue-specific expression of several apolipoprotein genes have been identified (reviewed in reference 50), but no information is available on the elements that govern the response of the apolipoprotein genes to nutritional stimuli.

A major finding of our study is that genetic obesity in Zucker rats abolishes the suppression of apoA-IV gene transcription by the fish oil diet. This result was a consistent finding in two sets of animals from different suppliers. Furthermore, this altered transcriptional regulation appears to be specific for the apoA-IV gene, since apoA-I gene expression decreased in both lean and obese rats in response to the fish oil diet. Thus, even though the genes coding for apoA-I and apoA-IV arose from an ancestral gene and share extensive sequence homologies (51), specialization in sequences conferring transcriptional suppression must have occurred.

As reported earlier for Sprague-Dawley rats (25), the sucrose-rich diet stimulates hepatic apoA-IV gene transcription in both lean and obese Zucker rats. Thus, the insensitivity of hepatic apoA-IV gene transcription in obese Zucker rats to regulation by dietary factors is not absolute, and some of the sequences involved in the regulation of gene expression by diets must be accessible to trans factors. Hence, major changes in the chromatin structure of the apoA-IV gene are probably not involved in the lack of transcriptional suppression in obese Zucker rats.

One possible mechanism for the defective response of the hepatic apoA-IV gene to a fish oil diet in obese Zucker rats is an altered intracellular balance of trans factors. The cis and trans factors by which obesity genes such as fa affect the transcription of other genes are largely unknown. However, some mechanistic insight has been presented for the reduced expression of adipsin, a serin protease, in adipose tissues of rodent obesity models. Studies in transgenic mice have shown that cis elements located within the promoter region mediate the response of the adipsine gene to the mouse db obesity gene, resulting in decreased transcription in adipose tissue (52).

An alternative mechanism, which is not exclusive of that above, relates to possible changes in signal transduction pathways mediating effects of dietary fish oil on gene expression. Among the numerous hormonal changes described in obese Zucker rats (reviewed in reference 53), hyperinsulinism, insulin resistance, high insulin/glucagon ratios, and increased plasma glucocorticoid levels may affect apoA-IV biosynthesis in rat liver $(43,54)$ and may, therefore, play a role in the altered regulation of apoA-IV gene transcription. Changes in thyroid hormone status are unlikely to abolish the suppression of apoA-IV gene transcription by the fish oil diet, since circulating thyroid hormone levels are reduced in obese Zucker rats (55) and hypothyroidism is characterized by decreased apoA-IV transcription (40). Omega-3 fatty acids contained in fish oil are thought to be the key mediators for reduced triglyceride synthesis and very low density lipoprotein secretion that is observed after a fish oil diet $(47,56)$. In livers of obese Zucker rats, the concentration of endogenous fatty acids is increased severalfold ( 57). Endogenous fatty acids may compete with the dietary omega-3 fatty acids and may, therefore, reduce or abolish the effects of omega- 3 fatty acids. 
In conclusion, obese ( fa / fa ) Zucker rats exhibit altered hepatic apoA-IV gene expression compared with lean $(\mathrm{Fa} /-)$ Zucker rats. On a basal diet, the maturation of apoA-IV mRNA is enhanced; on a fish oil diet, transcription from the apoA-IV gene is not suppressed. Since omega- 3 fatty acids are used as lipid-lowering regimens in humans and the obese Zucker rat is a model of human obesity, our findings may contribute to the understanding of the interactions of dietary and genetic factors in the regulation of plasma lipoprotein levels in humans.

\section{Acknowledgments}

The authors gratefully acknowledge the technical assistance of Milada Kickingereder and Birgit Ehrhardt.

This work was supported by Austrian Science Foundation grant P7944 MED, by Anton Dreher Gedächtnisschenkung der Universität Wien grant $157 / 90$, by two Research Grants from the Austrian Pediatric Society, by the USA-Austria Biomedical Exchange Program, and by U.S. National Institutes of Health grant HL-27341.

\section{References}

1. McNamara, D. J., R. Kolb, T. Parker, H. Batwin, P. Samuel, C. D. Brown, and E. H. Ahrens. 1987. Heterogeneity of cholesterol homeostasis in man. Responses to changes in dietary fat quality and cholesterol quantity. J. Clin. Invest. 79:1729-1739.

2. Katan, M. B., A. C. Beynen, J. H. M de Vries, and A. Nobels. 1986 Existence of consistent hypo- and hyperresponders to dietary cholesterol in man. Am. J. Epidemiol. 123:221-234.

3. Clarkson, T. B., M. G. Bond, B. C. Bullock, K. J. McLaughlin, and J. K. Sawyer. 1984. A study of atherosclerosis regression in Macaca mulatta. Exp. Mol. Pathol. 41:96-118.

4. Van Zutphen, L. F. M., and R. R. Fox. 1977. Strain differences in response to dietary cholesterol by Jax rabbits: correlation with esterase patterns. Atherosclerosis. 28:435-446.

5. Wagner, W. D., and T. B. Clarkson. 1974. Mechanisms of genetic control of plasma cholesterol in selected lines of Show Racer pigeons. Proc. Soc. Exp. Biol. Med. 145:1050-1057.

6. Boerwinkle, E., S. A. Brown, K. Rohrbach, A. M. Gotto, Jr., and W. Patsch 1991. Role of apolipoprotein $E$ and $B$ gene variation in determining response of lipid, lipoprotein, and apolipoprotein levels to increased dietary cholesterol. $\mathrm{Am}$. J. Hum. Genet. 49:1145-1154.

7. Xu, C. F., E. Boerwinkle, M. J. Tikkanen, J. K. Huttunen, S. E. Humphries, and P. J. Talmud. 1990. Genetic variation at the apolipoprotein loci contribute to response of plasma lipids to dietary change. Genet. Epidemiol. 7:261-275.

8. Williams, S. C., S. G. Grant, K. Reue, B. Carrasquillo, A. J. Lusis, and A. J. Kinniburgh. 1989. cis-Acting determinants of basal and lipid-regulated apolipoprotein A-IV expression in mice. J. Biol. Chem. 264:19009-19016.

9. Doolittle, D. A., A. J. Lusis, J. Lucero, and R. LeBoeuf. 1987. The apolipoprotein A-II structural gene controls A-II synthetic rate and size of high density lipoproteins. Circulation. 76:IV-222.

10. Reue, K., and T. H. Leete. 1991. Genetic variation in mouse apolipoprotein A-IV due to insertion and deletion in a region of tandem repeats. J. Biol. Chem. 266:12715-12721.

11. Srivastava, R. K., J. Tang, E. S. Krul, B. Pfleger, R. T. Kitchens, and G. Schonfeld. 1992. Dietary fatty acids and dietary cholesterol differ in their effect on the in vivo regulation of apolipoprotein A-I and A-II gene expression in inbred strains of mice. Biochim. Biophys. Acta. 1125:251-261.

12. Dallinga-Thie, G. M., P. H. E. Groot, and A. van Tol. 1985. Distribution of apolipoprotein A-IV among lipoprotein subclasses in rat serum. J. Lipid Res 26:970-976.

13. Green, P. H. R., R. M. Glickman, J. W. Riley, and E. Quinet. 1980. Human apolipoprotein A-IV. Intestinal origin and distribution in plasma. $J$ Clin. Invest. 65:911-919.

14. Wu, A.-L., and H. G. Windmueller. 1979. Relative contributions by liver and intestine to individual plasma apolipoproteins in the rat. J. Biol. Chem. 254:7316-7322.

15. Goldberg, I. J., C. A. Scheraldi, L. K. Yakoub, U. Saxena, and C. L. Bisgaier. 1990. Lipoprotein apoC-II activation of lipoprotein lipase. J. Biol. Chem. 265:4266-4272.

16. Lagrost, L., P. Gambert, S. Meunier, P. Morgado, J. Desgres, P. d'Athis, and C. Lallement. 1989. Correlation between apoA-IV and triglyceride concentration in human sera. J. Lipid Res. 30:701-710.
17. Haddad, I. A., J. M. Ordovas, T. Fitzpatrick, and S. K. Karathanasis. 1986. Linkage, evolution, and expression of the rat apolipoprotein A-I, C-III, and A-IV genes. J. Biol. Chem. 261:13268-13277.

18. Bray, G. A. 1977. The Zucker fatty rat: a review. Fed. Proc. 36:148-153.

19. Petit, D., S.-R. Wang, G. Renaud, and R. Infante. 1988. Lipoprotein secretion in lean and obese Zucker female rats in vivo and in a single-pass perfused liver preparation. Arch. Int. Physiol. Biochim. 96:51-62.

20. Pessah, M., C. Salvat, S. Wang, and R. Infante. 1987. In vitro synthesis of apoA-IV and apoC by liver and intestinal $\mathrm{mRNAs}$ from lean and obese Zucker rats. Biochem. Biophys. Res. Commun. 142:78-85.

21. Truett, G. E., N. Bahary, J. M. Friedman, and R. Leibel. 1991. Rat obesity gene (fa) maps to chromosome 5: evidence for homology with the mouse gene diabetes (db). Proc. Natl. Acad. Sci. USA 88:7806-7809.

22. Schonfeld, G., C. Felski, and M. A. Howald. 1974. Characterization of the plasma lipoproteins of the genetically obese hyperlipoproteinemic Zucker fatty rat. J. Lipid Res. 15:457-564.

23. Fukuda, N., M. J. Azain, and J. A. Ontko. 1982. Altered hepatic metabolism of free fatty acids underlying hypersecretion of very-low-density lipoproteins in the genetically obese Zucker rat. J. Biol. Chem. 257:14066-14072.

24. Witztum, J. L., and G. Schonfeld. 1979. Lipoproteins in the plasma and hepatic perfusates of the Zucker fatty rat. Diabetes. 28:509-516.

25. Radosavljevic, M., Y. C. Lin-Lee, S. M. Soyal, W. Strobl, C. Seelos, A. M. Gotto, and W. Patsch. 1992. Effect of sucrose diet on expression of apolipoprotein genes A-I, C-III and A-IV in rat liver. Atherosclerosis. 95:147-156.

26. Ribeiro, A., M. Mangeney, P. Cardot, C. Loriette, Y. Rayssiguier, J. Chambaz, and G. Bereziat. 1991. Effect of dietary fish oil and corn oil on lipid metabolism and apolipoprotein gene expression by rat liver. Eur. J. Biochem. 196:499-507.

27. Siedel, J., E. O. Hagele, J. Ziegenhorn, and A. W. Wahlefeld. 1983. Reagent for the enzymatic determination of serum cholesterol with improved lipolytic efficiency. Clin. Chem. 29:1075-1080.

28. Naegele, U., E. O. Hagele, G. Sauer, E. Widerman, P. Lehmann, A. W. Wahlefeld, and W. Gruber. 1984. Reagent for the enzymatic determination of serum triglycerides with improved lipolytic efficiency. J. Clin. Chem. Clin. Biochem. 22:165-174.

29. Mohan, P. F., F. C. Phillips, and M. P. Cleary. 1991. Metabolic effects of coconut, safflower, or menhaden oil feeding in lean and obese Zucker rats. Br. J. Nutr. 66:285-299.

30. Daniel, F., D. Morello, O. Le Bail, P. Chambon, Y. Cayre, and P. Kourilsky. 1983. Structure and expression of the mouse $\beta_{2}$ microgobulin gene isolated from somatic and nonexpressing teratocarcinoma cells. EMBO (Eur. Mol. Biol. Organ.) J. 2:1061-1065.

31. Feinberg, A. P., and B. Vogelstein. 1984. A technique for radiolabeling DNA restriction endonuclease fragments to high specific activity. Anal. Biochem. 137:266-267.

32. Lin-Lee, Y. C., Y. Tanaka, C. T. Lin, and L. Chan. 1981. Effects of atherogenic diet on apolipoprotein $\mathrm{E}$ biosynthesis in the rat. Biochemistry. 20:6474-6480

33. Thomas, P. 1980. Hybridization of denaturated RNA and small DNA fragments transferred to nitrocellulose. Proc. Natl. Acad. Sci. USA. 77:52015205.

34. Strobl, W., N. L. Gorder, G. A. Fienup, Y. C. Lin-Lee, A. M. Gotto, Jr., and W. Patsch. 1989. Effect of sucrose diet on apolipoprotein biosynthesis in rat liver: increase in apolipoprotein E gene transcription. J. Biol. Chem. 264:11901194.

35. Northemann, W., M. Heisig, D. Kunz, and P. C. Heinrich. 1985. Molecular cloning of cDNA sequences for rat $\alpha_{2}$-macroglobolin and measurement of its transcription during inflammation. J. Biol. Chem. 260:6200-6205.

36. Birch, H. E., and G. Schreiber. 1986. Transcriptional regulation of plasma protein synthesis during inflammation. J. Biol. Chem. 261:8077-8080.

37. Strobl, W., N. L. Gorder, Y. C. Lin-Lee, Gotto A. M., and W. Patsch. 1990. Role of thyroid hormones in apolipoprotein A-I gene expression in rat liver. J. Clin. Invest. 85:659-666.

38. Melton, D. A., P. A. Krieg, M. R. Rebagliati, T. Maniatis, K. Zinn, and M. R. Green. 1984. Efficient in vitro synthesis of biologically active RNA and RNA hybridization probes from plasmids containing a bacteriophage SP6 promoter. Nucleic Acids Res. 12:7035-7056.

39. Lamers, W. H., R. W. Hanson, and H. M. Meisner. 1982. cAMP.stimulates transcription of the gene for cytosolic phosphoenol-pyruvate carboxykinase in rat liver nuclei. Proc. Natl. Acad. Sci. USA. 79:5137-5141.

40. Lin-Lee, Y. C., W. Strobl, S. Soyal, M. Radosavljevic, M. Song, A. M. Gotto, and W. Patsch. 1993. Role of thyroid hormone in the expression of apolipoprotein A-IV and C-III genes in rat liver. J. Lipid Res. 34:249-259.

41. Kiledjian, M., and T. Kadesch. 1991. Post-transcriptional regulation of the human liver/bone/kidney alkaline phosphatase gene. J. Biol. Chem. 266:4207-4213.

42. Reue, K., D. Purcell, T. Leete, and A. J. Lusis. 1990. Genetic variation in apo A-IV mRNA levels is controlled post-transcriptionally by a combination of cis- and trans-acting regulatory elements. Circulation. 82:III-4. 
43. Elshourbaghy, N. A., M. S. Boguski, W. S. L. Liao, L. S. Jefferson, J. I. Gordon, and J. M. Taylor. 1985. Expression of rat apolipoprotein A-IV and A-I genes: mRNA induction during development and in response to glucocorticoids and insulin. Proc. Natl. Acad. Sci. USA. 82:8242-8246.

44. Staels, B., A. van Tol, G. Verhoven, and J. Auwerx. 1990. Apolipoprotein A-IV messenger ribonucleic acid abundance is regulated in a tissue-specific manner. Endocrinology. 126:2153-2163.

45. Nestel, P. J., W. E. Connor, M. F. Reardon, S. Connor, S. Wong, and R. Boston. 1984. Suppression by diets rich in fish oil of very low density production in man. J. Clin. Invest. 74:82-89.

46. Wong, S. H., P. J. Nestel, R. P. Trimble, G. B. Storer, R. J. Illman, and D. L. Topping. 1984. The adaptive effects of dietary fish and safflower oil on lipid and lipoprotein metabolism in perfused rat liver. Biochim. Biophys. Acto. 792:103-109.

47. Wong, S., M. Reardon, and P. Nestel. 1985. Reduced triglyceride formation from long-chain polyenoic fatty acids in rat hepatocytes. Metab. Clin. Exp. 34:900-905.

48. Iritani, N., E. Fukuda, K. Inoguchi, M. Tsubosaka, and S. Tashiro. 1980 Reduction of lipogenic enzymes by shellfish triglycerides in rat liver. J. Nutr. 110:1664-1670.

49. Blake, W., and S. D. Clarke. 1990. Suppression of rat hepatic fatty acid synthase and $S_{14}$ gene transcription by dietary polyunsaturated fat. J. Nutr. 120:1727-1729.
50. Zannis, V., D. Kardassis, P. Cardot, M. Hadzopoulou-Cladaras, E. E. Zanni, and C. Cladaras. 1992. Molecular biology of the human apolipoprotein genes: gene regulation and structure/function relationship. Curr. Opin. Lipidol. 3:96-113.

51. Luo, C.-C., W.-H. Li, M. N. Moore, and L. Chan. 1986. Structure and evolution of the apolipoprotein multigene family. J. Mol. Biol. 187:325-340.

52. Platt, K. A., H. Y. Min, S. R. Ross, and B. M. Spiegelman. 1989. Obesity linked regulation of the adipsin gene promoter in transgenic mice. Proc. Natl. Acad. Sci. USA. 86:7490-7494.

53. Argiles, J. M. 1989. The obese Zucker rat: a choice for fat metabolism Prog. Lipid Res. 28:53-66.

54. Uchida, E., A. Masumoto, S. Sakamoto, S. Koga, and H. Nawata. 1991. Effect of insulin, glucagon or dexamethasone on the production of apolipoprotein A-IV in cultured rat hepatocytes. Atherosclerosis. 87:195-202.

55. Durbin-Naltchayan, S., J. Bouhnik, and R. Michel. 1983. Thyroid status in the obese syndromes of rats. Horm. Metab. Res. 15:547-549.

56. Wong, S., and P. J. Nestel. 1987. Eicosapentaenoic acid inhibits the secretion of triacylglycerol and of apoprotein B and the binding of LDL in Hep G2 cells. Atherosclerosis. 64:139-146.

57. Azain, M. J., N. Fukuda, F.-F. Chao, M. Yamamoto, and J. A. Ontko. 1985. Contributions of fatty acid and sterol synthesis to triglyceride and cholesterol secretion by the perfused rat liver in genetic hyperlipidemia and obesity. $J$. Biol. Chem. 260:174-181. 